\title{
O CURSO DE GRADUAÇÃO DA ESCOLA DE ENFERMAGEM DA UFRJ - CURRÍCULO PLENO FACE AO PARECER 163/72
}

\author{
Maria Dolores Lins de Andrade * \\ Cilei Chaves Rhodus * \\ Elvira De Felice Souza * \\ Lygia Paim * \\ Wilma Carvalho *
}

Introdução:

Ao atender o convite da Comissão de Temas do XXV Congresso Brasileiro de Enfermagem para apresentar trabalho sobre o Currículo Pleno do Curso de Graduação em Enfermagem, os autores se propõem atingir os seguintes objetivos:

- Informar os participantes deste conclave sobre o currículo pleno do curso de graduação, em desenvolvimento da Escola de Enfermagem da Universidade Federal do Rio de Janeiro, segundo o que Estabeiece o Parecer 163/72. (D.O. 21.2.1š72, p. 1423);

- Caracterizar a posição da Escola quanto ao Ensino de Graduação, diante das tendências da educação e do exercício da Enfermagem;

- Identificar certas limitaçōes e possibilidades configuradas na aplicação do atual currículo.

Para facilitar a exposição do tema, o trabalho foi dividido em três partes:

I. $^{\mathrm{a}}$ - INTRODUÇÃO - Constitui-se de objetivos e Plano Geral do Trabalho.

II. $^{\text {a }}$ - DESENVOLVIMENTO DO TEMA - Abrange a apresentação do Currículo Pleno do Curso de Graduação em desenvolvimento na Escola de Enfermagem da UFRJ;

* Professoras da Escola de Enfermagem da Universidade Federal do Rio de Janeiro. 
- a posição da Escola quanto ao ensino de graduação diante das tendências da educação e do exercício da enfermagem;

- e a identificação de dificuldades e implicações configuradas no atual currículo.

III. $^{\text {a }}$ - CONCLUSÃO - Salienta os pontos que seviram de base para sugestões e recomendações.

Antes de procedermos à apresentação do Currículo Pleno do Curso de Graduação que está sendo desenvolvido na Escola de Enfermagem da UFRJ desde 1972, cabe submeter a um balanço crítico alguns aspectos da organização curricular adotada.

Por motivos ligados à exiguidade de tempo e à objetividade da exposição, ater-nos-emos, primeiramente, a algumas implicações ligadas à estrutura e desenvolvimento currícular como ponto de partida para caracterizar a posição da Escola face ao Ensino de Graduação, diante das exigências de uma sociedade em processo de mudança e principalmente, diante das determinações legais vigentes.

Se tomarmos como referência a conceituação de Currículo formulada pela $3 .^{\text {a }}$ Conferência Pan-Americana de Educação Médica, cujos termos especificam que "o currículo engloba tudo que diz respeito aos aspectos gerais e particulares do ensino e da aprendizagem, suas relações íntimas com a investigação, conteúdo dos programas e planos de estudo, utilização das cargas horárias, adaptação do pessoal docente, adequação às disponibilidades materiais e perspectivas de desenvolvimento do corpo social", não será difícil deduzir e aceitar como válido que a organização curricular adotada, no que tange à sua aplicação, apresenta, se não em todos, pelo menos em alguns aspectos, certas implicações qus contradizem algumas proposições contidas no acima referido enunciado.

- Quanto aos aspectos gerais e particulares do Ensino e aprendizagem: prevalecem ainda as idéias relativas a uma educação sistemática e tradicional e uma certa resistência às inovações.

- Quanto à investigação, destacamos:

- falta de pessoal preparado;

- limitação de recursos e oportunidades para o preparo de pessoal docente;

- carência de recursos para a realização de pesquisas.

- Quanto aos Programas e Planos de Estudo:

- ainda há repetição de assuntos;

- predomina o enfoque nas entidades nosológicas e procedimentos técnicos; 
- a correlação entre a teoria e a prática do ensino nem sempre é alcançada;

- nem sempre existe correlação entre a temática abordada e a problemática de saúde nacional, regional e local.

- Quanto à utilização das cargas horárias:

- a carga horária teórica-prática, dedicada às atividades de ensino-aprendizagem desenvolvidas nos Campos Clínicos, parece não estar sendo devidamente utilizada quanto ao entendimento das necessidades formativas do estudante em razão das deficiências de recursos materiais e humanos nos Serviços de Saúde.

- Quanto à adaptação do pessoal docente sobressaem-se aspectos legais e de desenvolvimento de pessoal:

- A seleção de novos elementos depende do número de vagas existentes.

- A indicação de docentes para o período probatório (Auxiliar de Ensino), Departamentos, não dispõe ainda de sistema em que se utilizam apenas critérios objetivos.

- O provimento das vagas iniciais da carreira do Magistério Superior, por Auxiliares de Ensino em atividade, prende-se à determinação legal de comprovar no prazo máximo de 4 anos a partir da. data de sua admissão, ser portador de certificado de aprovação єm Curso de Pós-Graduação, enquanto que o das classes do Magistério Superior e Professores contratados, aos mesmos níveis, está na dependência do credenciamento dos cursos de doutorado e/ou abertura dos Concursos de Docência Livre.

- Os aspectos de desenvolvimento pessoal estão ligados a possibiiidades da Instituição à qual os docentes estão vinculados e, paralelamente, à dotação individual dos mesmos.

- Quanto às disponibilidades materiais e ao desenvolvimento do Corpo Social:

A implantação do Centro de Ciências da Saúde no Campus Universitário, iniciada com a mudança das Diretorias das Unidades, tem exigido que todo o Corpo Social da Escola participe em termos de contribuição ao processo e de ajustamento a certas dificuldades na vtilização de recursos materiais e humanos. Pretende-se que em 1974 grande parte desses recursos estejam centralizados, através dos Departamentos, no Hospital Universitário. Duas linhas de ação previstas pela Reforma estão sendo implementadas visando ao desenvolvimento do Corpo Social:

- O fortalecimento das sub-unidades didático-pedagógicas e pesquisa (Departamentos) ; 
- a Coordenação, a nível do Centro de Ciências da Saúde, de todos os recursos humanos e materiais.

Com base nestas considerações, vale acrescentar que as dificuldade apontadas demonstram que há defasagem entre a organização Curricular adotada e sua aplicação, principalmente nos Campos Clínicos. Isto porque há hiatos em torno:

- daquilo que se pensa fazer;

- do que se faz;

* e do que se deveria fazer - representados no desenvolvimento curricular entre o que o corpo docente planeja e o que realiza; Clínico;

- entre os ensinamentos de classe e a aplicação em Campo

- entre os objetivos gerais do ensino e os objetivos operacionais da aprendizagem.

A despeito de todas essas limitaçōes, podemos afirmar que o Currículo Pleno de Graduação em Enfermagem é bastante avançado para o momento presente, em termos de enriquecimento, quanto ao elenco de disciplinas obrigatórias; e eletivas de Ciclo Pré-Profissional com Cièncias Básicas da Área da Saúde; de Ciclo Profissional, com Habilitações oferecendo opção para diversas áreas; de complementação pedagógica para Capacitação ao ensino de $10^{\circ}$ e $2 .^{\circ}$ graus facilitando, portanto, a adequação do Ensino de Enfermagem às necesciclades do educando, aos objetivos e finalidades da profissão e à demanda do Mercado de Trabalho.

\section{II - DESENVOLVIMENTO DO TEMA}

A ADMINISTRAÇÃO TÉCNICO-PEDAGÓGICA DA U.F.R.J. E IMPLICAÇÕES DECORRENTES

- Sistema de Crédito na Universidade Federal do Rio de Janeiro. O sistema de Crédito na U.F.R.J. foi estabelecido de acordo com as resoluções do CEG (Resoluções 1/69 e 15/71) nas quais foi adotado como Conceito, que "o Crédito dá uma medida do número de horas que a disciplina ocupa dentro do currículo". Assim, a uniciade de Crédito corresponde a:

1 CRÉDITO $=1 \mathrm{~h} /$ semana em 1 período letivo (15 semanas) $=15$ horas

O trabalho escolar equivalente ,definido por estas Resoluções, corresponde a:

1. Atividades teórico-práticas.

1 CRÉDITO $=2 \mathrm{~h} /$ semanas em 1 período letivo (15 semanas) $=30$ horas 
2. Atividades Clínicas e de Campo:

1 CRÉDITO - 3h/semanas em 1 período letivo (15 semanas)

$=45$ a 90 horas fixadas pelo Departamento.

O sistema de Crédito, assim entendido, implica para o desenvolvimento curricular de Enfermagem que:

- embora o curso de enfermagem seja sequencial por natureza, Esse sistema permite certa liberdade individual de seleção de disciplinas por período, desde que haja condiçōes e disponibilidades. tais como: le:tivo;

- maior número de ofertas de disciplinas em cada período

- docentes orientadores preparados e em número suficiente para aconselhar o estudante no seu planejamento curricular.

- Tomando por base o trabalho do professor, este Sistema de Crédito omite quase que por completo o esforço que o aluno realiza para a aquisição cumulativa das medidas correspondentes, quando. na realidade esse esforço é o elemento básico para a determinação da Unidade de Crédito. Consequentemente, vem observando que a Unidade de Crédito é entendida principalmente em termos de Carga horária pré-estabelecida para a Disciplina. Na área específica de Enfermagem, observa-se que, diante da integralização prevista, ocorre uma desvalorização do Crédito nas Atividades Clínicas e de Campo, ccasião em que o aluno realiza um esforço maior para obtenção do. mesmo.

- A indicação dos métodos da avaliação para os diferentes tipos tarefas discentes compete ao professor da disciplina, o qual, sentindo-se limitado pelo cumprimento efetivo da Carga horária pré-estabelecida, seja nas atividades de Classe ou de Campo, encontra sérias dificuldades para medir e valorizar devidamente o esforço. realizado pelo aluno para a obtenção do Crédito.

Por exemplo: no 3..$^{\circ}$ período do Tronco Profissional Comum, as disciplinas são assim distribuídas: 


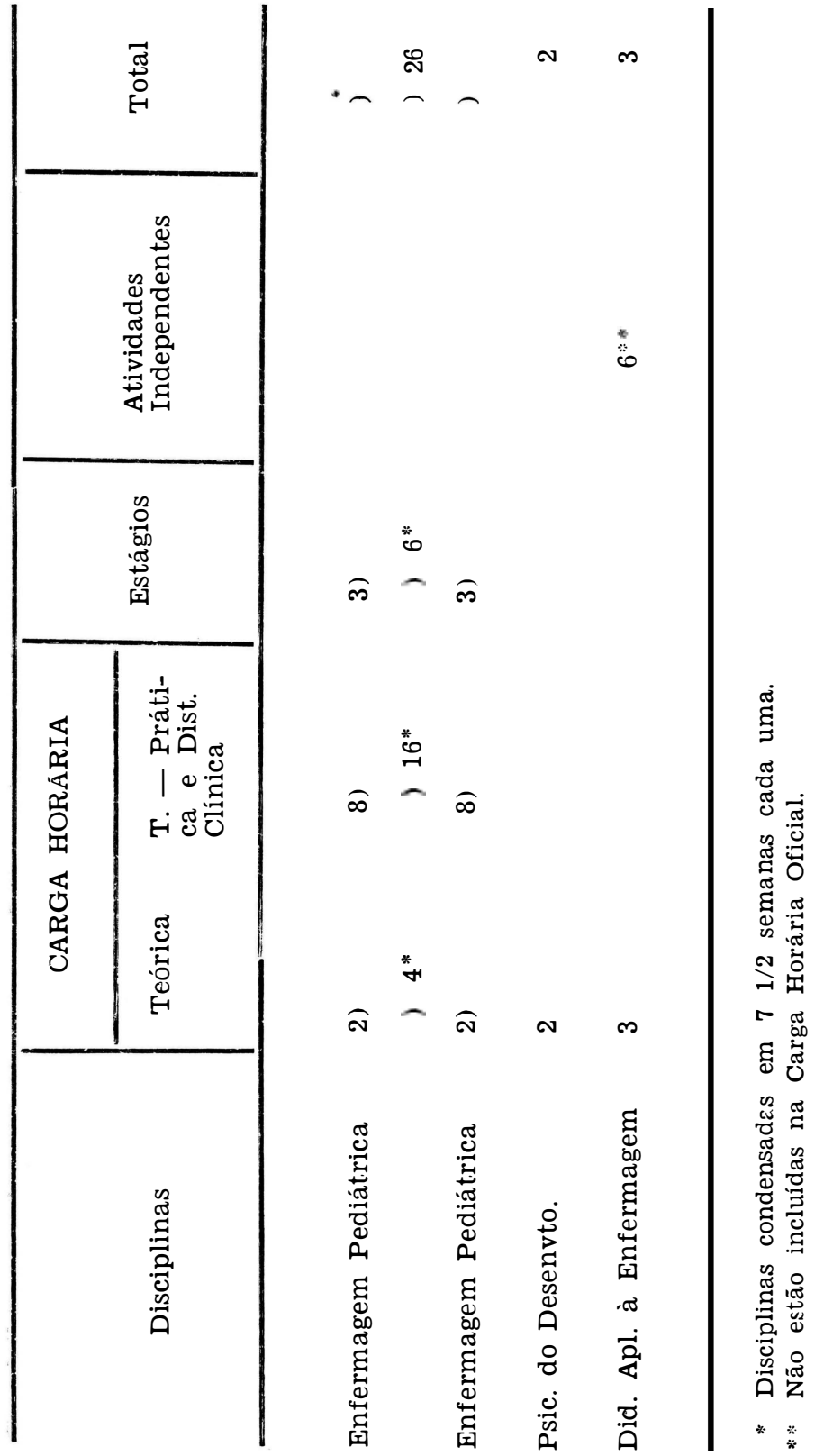


- Administração Acadêmica: a determinação de épocas para os atos da Administração Acadêmica, a nível dos Conselhos Superiores da Universidade, veio sistematizar a distribuição e escalonamento das Disciplinas dos Currículos, fixando datas para:

- divulgação do elenco de disciplinas ofertadas para período;

- matrícula;

- inscrição para disciplina - substituição de disciplinas;

- trancamento de inscriçōes em disciplina;

- remessa de notas finais referentes à avaliação das disciplinas por semestre letivo, já incluindo o prazo para remoção do Grau I (incompleto);

- transferências, matrícula com isenção de Exame Vestibular e Re-Matrícula.

- A Coordenação do Ensino é exercida através de Conselhos de Cursos, dos quais funcionam na Escola: o de Cursos de Graduação e o de Cursos para Graduados. No Curso Graduação em Enfermagem, a responsabilidade pela coordenação de todas as atividade didáticopedagógicas para efeito de planejamento do Currículo e desenvolvimento dos planos de ensino, através dos Departamentos, cabe a um Conselho, formado pelos Chefes dos Departamentos, presidido por um Coordenador, com representação do Corpo Discente. Entretanto, ainda que a constituição do Conselho dos Cursos de Graduação em Enfermagem seja considerada bastante representativa dos responsáveis pela ministração direta do ensino na área profissional, sofre dificuldades significativas quanto à integração dos docentes das demais Unidades da U.F.R.J. que participam na ministração dos referidos Cursos: Instituto de Microbiologia, Fac. de Letras Instituto de Ciências Biomédicas, Instituto de Psicologia, Instituto de Nutrição, Instituto de Ciências Sociais, Faculdade de Educação.

Isto, pelo que tange ao desenvolvimento curricular do Curso de Graduação em Enfermagem, tem ocasionado uma série de problemas que ainda não puderam ser resolvidos, tais como:

- A previsão de horas-aula para o aluno é maior do que a sua utilização efetiva, acrescencio em tempo a duração do Ciclo Pré-Profissional principalmente para o aluno matriculado em regime de tempo integral;

- Não obstante as determinações legais no que diz respeito aos propósitos do Ciclo Pré-Profissional visem a um tronco comum de estudos para todos os Cursos da Área da Saúde com as finalidades de: 1) - suprir as insuficiências do concurso vestibular e 2) - realizar estudos básicos para os ciclos posteriores.

Na realidade, o que vem sendo observando é que o preparo bá- 
sico para as disciplinas do Ciclo Profissional não corresponde, totalmente, aos propósitos do Curso de Graduação em Enfermagem;

- O trabalho independente do aluno, quanto ao desenvolvimento das atividades discentes e de tarefas específicas para avaliação visando a obter Créditos, não tem sido considerado devidamente por ocasião da distribuição da carga horária de cada disciplina;

- A diversificação de abordagem com os alunos dos diversos cursos ministrados, dentro e fora da Escola de Enfermagem, tem acarretado dificuldades administrativo-pedagógicas para a Coordenação do ensino e situações de conflito para o aluno, principalmente por motivos ligados ao processo de reestruturação das Unidades e Implantação dos Centros Universitários.

- Desdobramentos em ciclos: A distribuição do Curso de Gracuação em Enfermagem, em partes sucessivas, veio permitir um desenvolvimento curricular mais adequado diante da aplicação dos princípios didático-pedagógicos, no que se refere à correlação, sequencia e ordenação, conteúdo programático, seleção de experiêncías, métodos de ensino, medidas e avaliação das disciplinas. Assim é que oo final de cada ciclo, podem ser traduzidos em comportamentos finais, alguns dos objetivos como os seguintes:

I.o Ciclo de Estudos Universitários (Ciclo Básico ou Pré-Profissional) :

- Definir a opção feita para a Área da Saúde, atingida por classificação no Concurso Vestibular, ratificando a escolha para a profissão;

- Reconhecer a situação de saúde do país a nível local, regional e nacional;

- Identificar as características do ambiente terapêutico e compartar-se como observador participante;

- Aplicar conhecimentos fundamentais, princípios e métodos científicos para as ações de Saúde;

- exercitar-se na coleta de dados, através da aplicação de instrumentos básicos de investigação na área da Saúde;

Estes objetivos determinam algumas implicaçōes se se levar em conta a política educacional de acesso à Universidade, o contexto sócio-econômico - cultural ligado à clientela que ingressa na mesma, as potencialidades e as experiências anteriorres do educando. Uma dessas implicações é que o vestibular unificado criou um problema pedagógico, quanto à opção para a carreira profissional que pode não coincidir com a vontade do próprio educando. Em conseqüência, cabe à Escola propiciar elementos de informação sobre a enfermagem e oportunidades que permitam ao educando não apenas a re- 
fcrmulação de conceitos mas também a ampliação quanto às perspectivas da profissão. Outra implicação está ligada aos recursos que tem por objetivos assegurar ao estudante adequadas condições de estudo e trabalho intelectual, bem como ao atendimento de suas necessidades econômicas e sociais, os quais se encontram atualmente decentralizados. Esta descentralização dificulta o acesso aos diferentes locais de aplicação do ensino, a comunicação, a racionalização das atividades docentes e discentes, invalidando desse modo alguns aspectos do desenvolvimento curricular, principalmente no que se refere à interação docente-aluno, tão necessária às mudanças de comportamento desejáveis e imprescindíveis à definição de um ambiente terapêutico. Tendo em vista as potencialidades e as experiências anteriores do estudante, uma terceira implicação vem, por si só, constituindo um dos grandes desafios para o desenvolvimento curricular e para a dinâmica e racionalidade do próprio processo educativo. Isto porque, o êxito dos planos de ensino. quer nas atividades de classe ou de Campo, depende, em grande parte, da valorização que se deve dar ao estudante como indivíduo e, especificamente, como centro de interesse do processo educativo, pelo que tange às suas potencialidades e experiências anteriores.

Ademais, o elenco de disciplinas integrantes desse I. ${ }^{\circ}$ Ciclo, a relação professor - aluno nas atividades práticas, os instrumentos e recursos técnicos disponíveis para o desenvolvimento do ensino, vêm impedindo a formação integral do estudante, para o exercício de atividades técnico-científicas, destacadamente aquelas que atenderiam aos propósitos do desenvolvimento da curiosidade intelectual voltada para a investigação, os trabalhos de grupo e as perspectivas de uma educação continuada.

\section{Ciclo de Estudos Universitários (Ciclo Profissional)}

De acordo com as funções mais importantes que uma enfermeira a'esempenha, existem comportamentos finais a serem esperados dos estudantes ao fim dos Programas de Ensino do Ciclo Profissional, quais sejam: magem.

- Atuar como enfermeira no processo de assistência de enfer-

- Identificar as necessidades de saúde do indivíduo, família e comunidade;

- Fazer o diagnóstico de enfermagem;

- Elaborar o plano de cuidados;

- Executar ou delegar a execução de alguns cuidados;

- Avaliar a qualidade da assistência de enfermagem;

- Atuar como membro da equipe de Saúde e como líder da equipe de enfermagem; 
- Interpretar a enfermagem para a equipe multiprofissional;

- Assessorar a equipe multiprofissional para assuntos de enfermagem;

- Integrar as ações profissionais nos programas de Assistência de Enfermagem;

- Coordenar as ações de enfermagem nos programas de Assistência à Saúde;

- Liderar os programas de Assistência de Enfermagem.

- Atuar como educadora;

- Planejar, executar e avaliar programas de ensino para orientação à saúde de indivíduos, famílias, Comunidade, e Treinamento de pessoal de Enfermagem;

- Administrar Serviços de Enfermagem;

- Coletar dados e análisá-los com o fim de organizar e reorganizar Unidades de Enfermagem;

- Participar na elaboração de normas, rotinas e roteiros de Unidades de Enfermagem;

- Supervisionar pessoal auxiliar de enfermagem;

- Coordenar e controlar as ações de enfermagem a nível de Unidade ou de Serviço;

- Avaliar a qualidade da assistência de enfermagem e implementar os planos de cuidados;

- Assumir posições de liderança para as quais for indicada.

Em geral, o que se pode observar quanto ao desenvolvimento curricular no Ciclo Profissional é que a aplicação dos programas das disciplinas não está ocorrendo até o presente, de modo que assegure completamente o alcance dos objetivos operacionais tangíveis ao papel que cabe a enfermeira nas equipes multiprofissionais, nos programas de Assistência à Saúde e reabilitação, e consequentemente nos planos de desenvolvimento social e cultural. Com efeito, as oportunidades que poderiam garantir aos estudantes cxperiência suficiente para adquirir habilidade, quanto ao desempenho da função de atuar como enfermeira no processo de Assistência de Enfermagem, são falhas em muitos aspectos principalmente por motivos ligados a diversas áreas clínicas que comportam - Campo próprio da Prática profissional, de modo geral da Equipe cie Saúde, e muito particular da Equipe de Enfermagem.

Por isso mesmo, um grande esforço tem sido dispendido no sentido de oferecer condiçōes e oportunidades ao estudante, para a aquisição de comportamentos que correspondam a sua atuação como enfermeiro no processo de Assistência de Enfermagem. No entanto, se bem que muitas tentativas sejam feitas para assegurar €xperiências de aprendizagem em todas as fases do processo, du- 
rante aplicação dos programas das disciplinas de enfermagem, podemos afirmar que as oportunidades ocorrem com maior frequência e propriedade na fase de execução de cuidados dirigidos, para as necessidades imediatas do paciente-família.

Com relação a função de atuar como membro da equipe de sauide e líder da equipe de enfermagem, as maiores dificuldades para a aplicação curricular decorrem de problemas e implicações relativos não apenas à limitação de oportunidades concretas para o exercício de experiências de aprendizagem, mas, principalmente, da inexistência de "situações-modelo" em contraposição à existência "situações-de-fato" que, geralmente, não permitem a adequada participação do estudante. em termos de aquisição de comportamentos previstos como significativos e desejáveis ao desempenho de atividades referentes a essa função.

Por outro lado, têm sido oferecidas oportunidades, no sentido de permitir ao estudante a aquisição de comportamentos desejáveis ao desempenho da função de educador, dentre as quais está a prática de métodos didáticos, em diferentes situaçōes de aprendiragem, e que lhe permite incorporar elementos básicos como a linguagem didática, a utilização de meios e recursos auxiliares, e atitudes equivalentes a uma ação didática organizada.

Além disso, o correlacionamento do ensino das disciplinas peciagćgicas com as disciplinas de enfermagem, especialmente as que se referem às áreas materno-infantil, de saúde pública, de administração, bem como a concessão de Bolsas de Monitoria. têm servido de estímulo à aquisição desses comportamentos.

Desde que a função de administrar serviços de Enfermagem exige do enfermeiro o desempenho de atividades complexas que visam principalmente à manutenção da liderança junto à equipe de enfermagem, quer nas Unidades ou nos Serviços Correspondentes, as experiências de aprendizagem carecem de seleção apropriada à aquisição dos comportamentos específicos. Sucede que, em virtude las implicaçōes ligadas a problemas e dificuldades nas áreas clíricas que presentemente servem de campo para atividades teóricopráticas estágio, as oportunidades oferecidas ao estudante para aquisição e domínio de conhecimentos, desenvolvimento de habilic.ades e incorporação de atividades coerentes com as responsabilidades exigidas da enfermeira, não atendem completamente os objetivos operacionais explicitamente propostos para o desenvolvimento dos planos de ensino. Os problemas e dificuldades, aqui questionados serão tratados minuciosamente na seção relativa a Campos Clínicos. Já com referência à função de realizar estudos sobre problemas de enfermagem e participar de pesquisas na área da saúde, cabe-nos informar que todas as disciplinas de enfermagem têm prorurado, de alguma forma, oferecer ao estudante, oportunidades para 
desenvolver atitudes e habilidades coerentes com o trabalho científico e com a efetiva participação nas pesquisas aplicadas na da área da Saúde.

Finalmente, no que concerne às oportunidades que são oferecicas ao estudante para aquisição de comportamentos apropriados à função de participar de Associações de Classe, Sociedades cientificas $e$ culturais, podemos afirmar que, especificamente, durante o desenvolvimento dos programas de ensino de algumas disciplinas como Histó ria da Enfermagem, Ética Profissional, Exercício Porfissional e Legislação da Enfermagem, certas experiências têm sido selecionadas com o fim de despertar a motivação e levar os estudantes à participação na vida associativa. Procura-se conseguir motiva-los pela leitura, análise e resumos de artigos da Revista Brasileira de Enfermagem, pela elaboração de trabalhos escritos, para apresentação individual e em grupo ou ainda, pela apresentação de relatórios escritos após o respectivo comparecimento aos encontros profissionais promovidos pela ABEn.

\section{CAMPOS DE EXPERIÊNCIA PRÁTICA}

Das dificuldades encontradas nos campos de experiência prática decorre, sem dúvida alguma, a maior soma de implicações para o desenvolvimento curricular. Dentre estas, as que assumem importância mais significativa, a nosso ver, estão vinculadas aos seguintes problemas:

- Ausência de campos que sejam adequados ao desenvolvimento das atividades teórico-práticas dos programas de ensino no âmbito da Universidade;

- Os Serviços de Saúde que são utilizados para aplicação prática dos diversos programas das disciplinas de enfermagem não permitem, de modo geral, o atendimento dos critérios que servem à seleção e à organização das experiências de aprendizagem, apropriadas ao preparo profissional do estudante;

- A insuficiência quantitativa de docentes para o desenvolvimento curricular das experiências em Campo de Prática vêm prejudicando a qualidade do ensino das várias disciplinas de enfermagem;

- A seleção das oportunidades encontradas nos campos de prática que servem aos propósitos do desenvolvimento das experiências da aprendizagem, da avaliação do rendimento escolar e da posterior verificação do alcance dos objetivos operacionais, depende, em larga escala, do preparo específico dos docentes e mais particularmente da capacidade dos mesmos para avaliar e resolver os problemas peculiares que surgem nas etapas sucessivas do desenvolvimento curricular; 
- A relação professor-aluno no Campo de Prática tal como prevista pela UFRJ, no que tange aos princípios básicos, não atende a todas as exigências do ensino de enfermagem.

De modo geral as implicações decorrentes desses problemas apresentam aspectos que podem ser considerados sob pontos de vista diversos.

Um aspecto positivo é evidenciado precisamente pela inexistência de campos de prática adequados à aplicação curricular o que tem servido de motivo para a escola ampliar o seu campo de ação até o âmbito da Comunidade; isto, como sabemos. vem ao encontre de um dos propósitos básicos da Universidade. Acreditamos que essa situação tenda a persistir face à crescente demanda de alunos matriculados nos períodos letivos, a qual vem excedendo de mareira contínua a capacidade disponível dos campos de prática, na área da Universidade. Por outro lado, um aspecto negativo ocorre para o ensino, qual seja o nível de assistência de enfermagem, nos referidos campos de prática. Estes, ainda não atingiram o desejável em termos de padrões mínimos recomendáveis ao êxito do desenvolvimento curricular do Curso de Graduação de Enfermagem. Por esta razão, os docentes vinculados às atividades de Campo vêm participando cada vez mais na resolução de problemas próprios da assistência de enfermagem e, na medida do possível, mobilizando esforços no sentido de ajustar-se à equipe de saúde dessas Instituições, através do fortalecimento de dois polos de interesse valorizados pela Escola:

- Assessoria às Chefias de Enfermagem;

- Co-participação nos Programas de Treinamento de Pessoal de Enfermagem.

As consequências dessas implicações não têm sido totalmente favoráveis à qualidade do ensino de enfermagem, ocasionando, outrossim, prejuízos para o crescimento profissional do corpo docente $f$ para o desenvolvimento integral do aluno.

U.F.R.J.

ESCOLA DE ENFERMAGEM ANA NERI

CURRÍCULO PLENO DO CURSO DE GRADUAÇÃO EM ENFERMAGEM E OBSTETRICIA

Na forma do que dispōe o artigo 26 da Lei 5.540 de 28/11/1968, tendo em vista o Parecer 193/72 - Aprovado em 28/1/1972.

a) PRÉ-PROFISSIONAL (Ciclo Básico)

Perícdos $=3$ a 4 


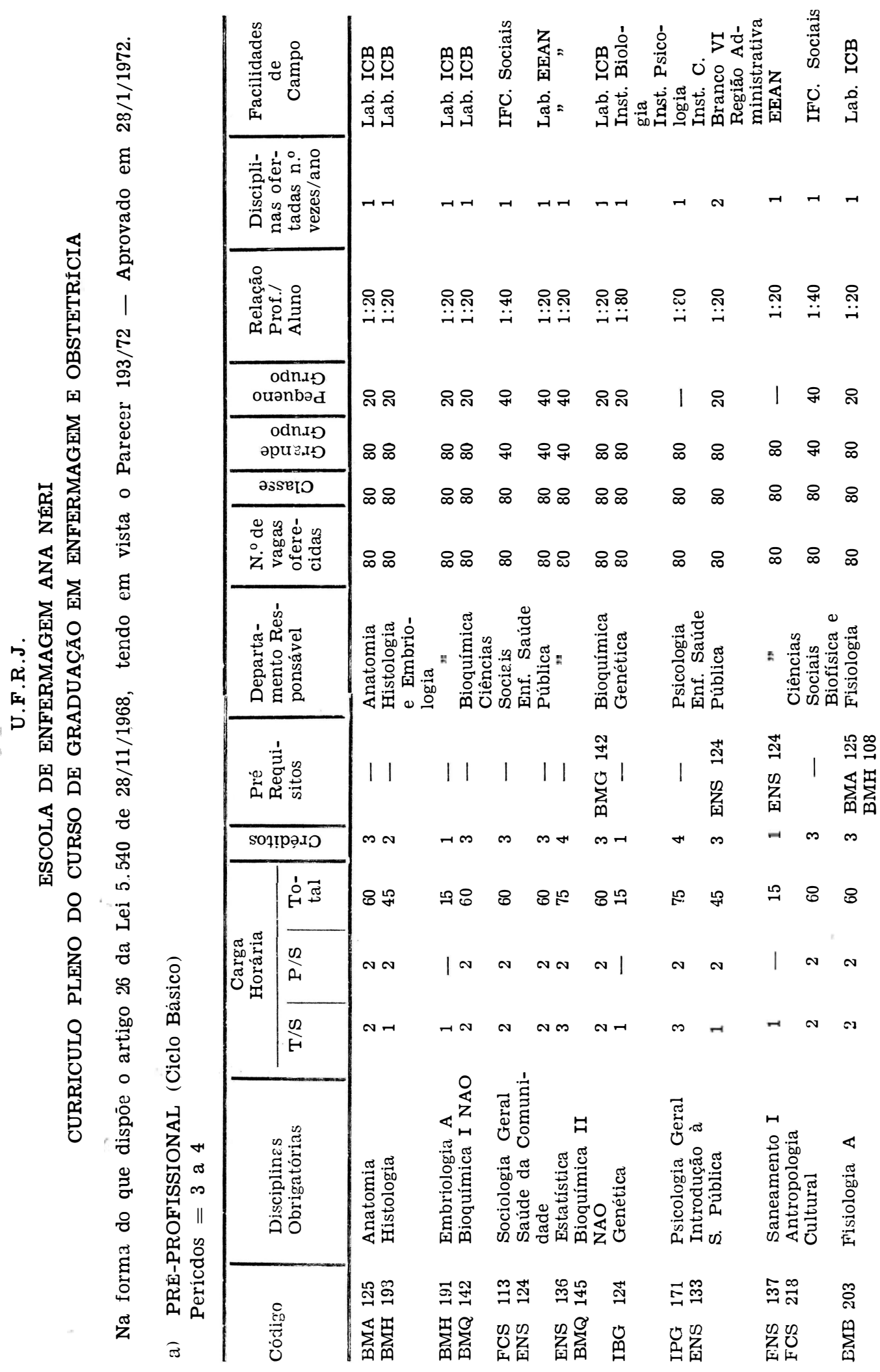




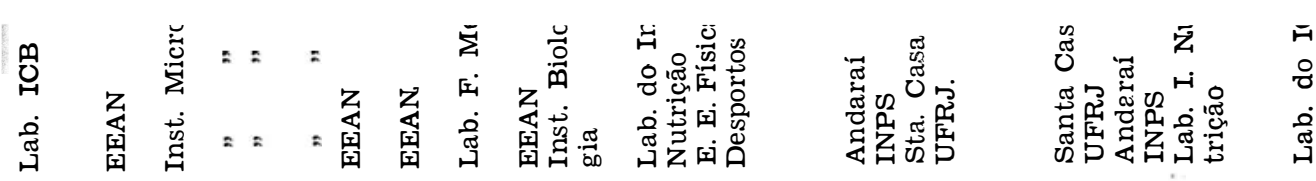

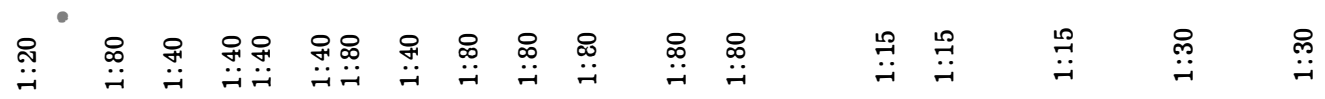

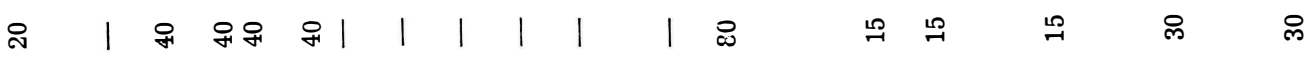

이 வ 8 வ

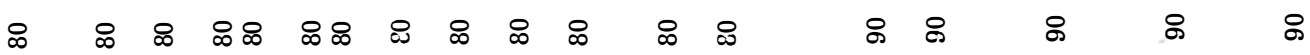

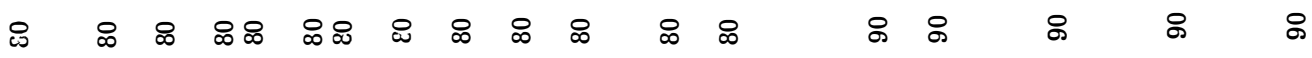

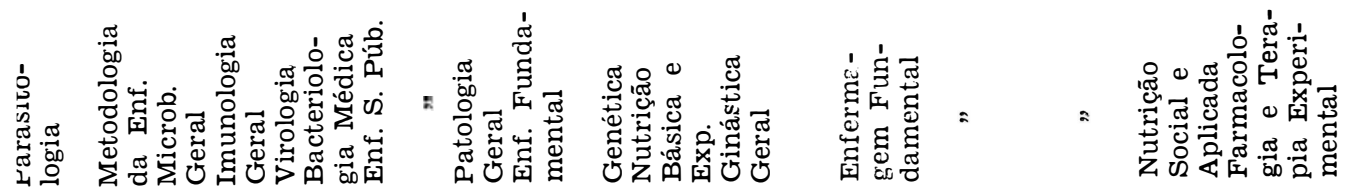

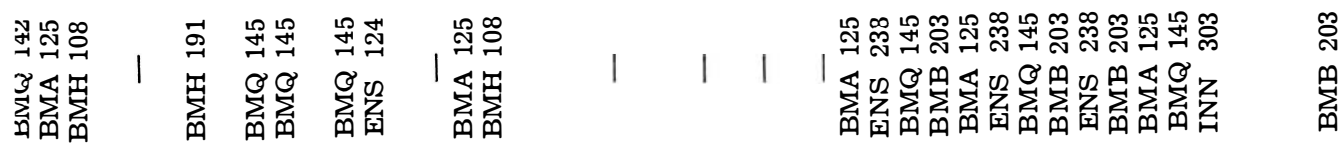

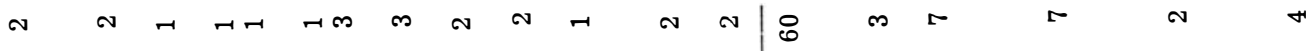

누 \& 8 \& \& 8 \&

N $\mid$ n n N N

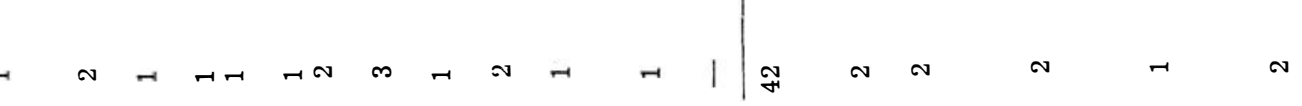

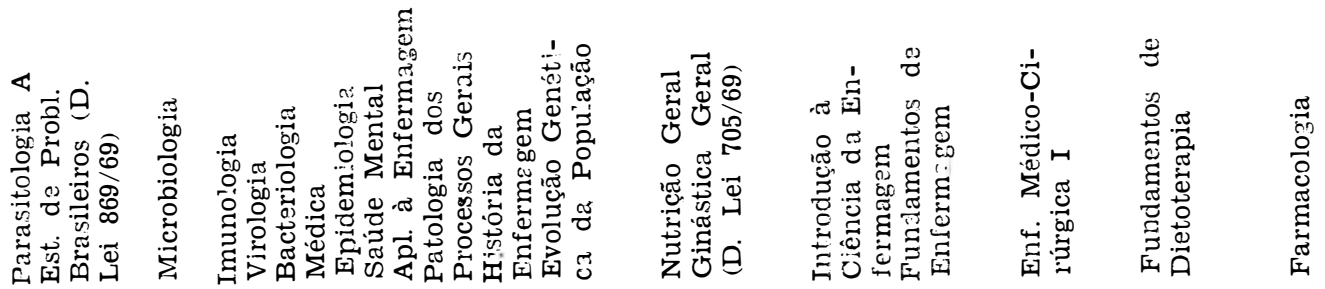

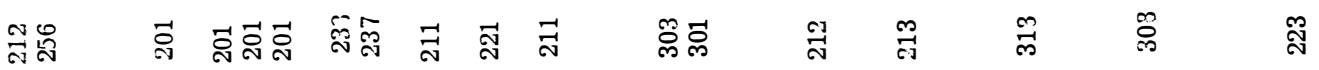

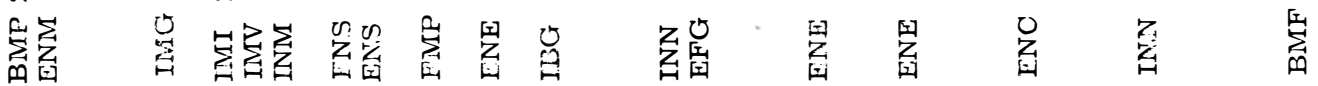




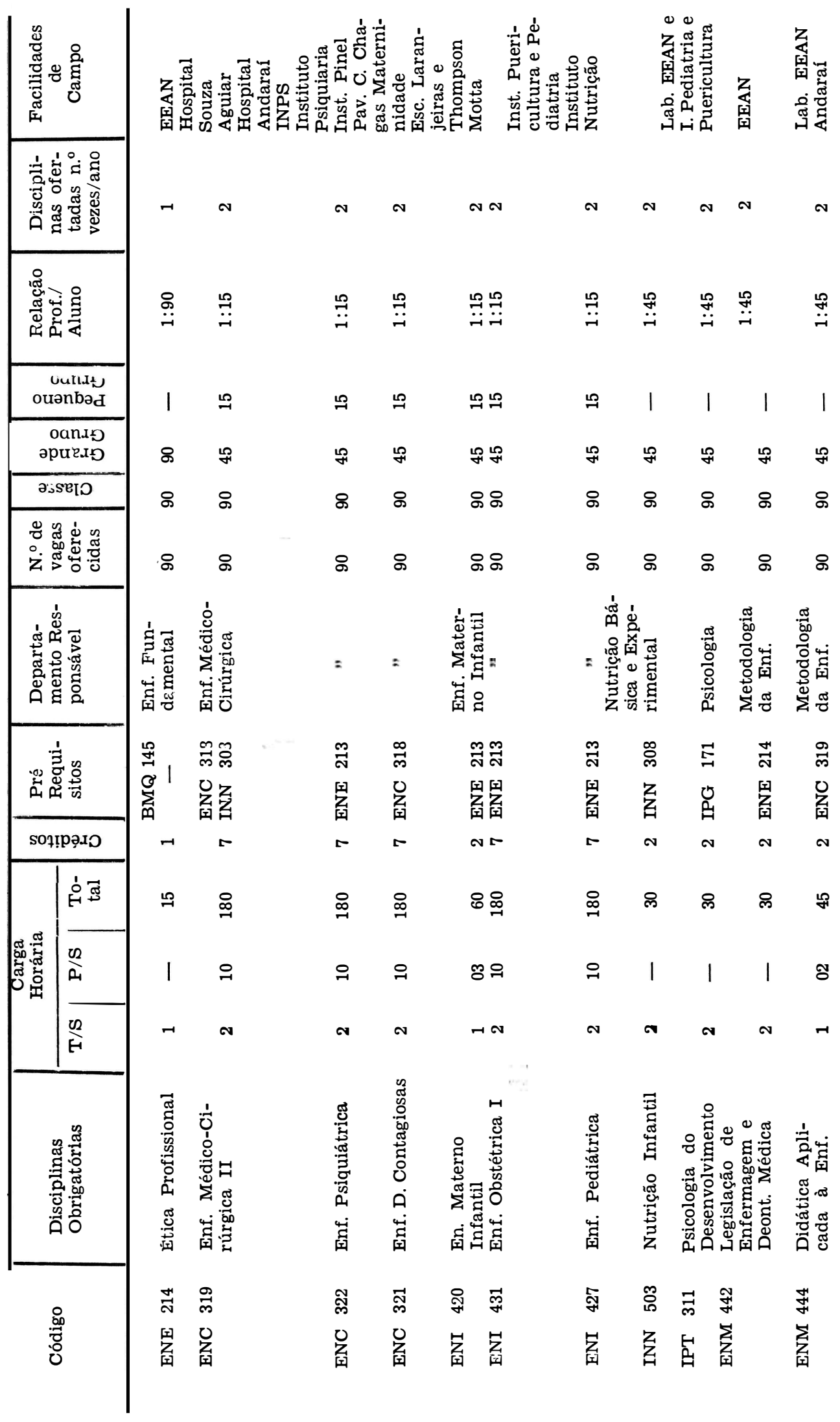


ง $\rightarrow$ ก

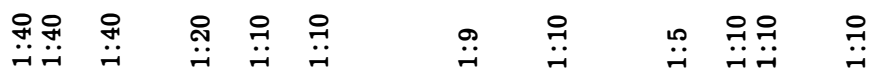

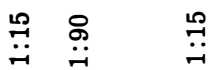

아아앙으으

응 10 으음 우

요 웅

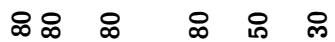

요 웅

ลิ ํํำ 오

요 우

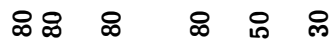

와 앙

ㅇํ 운ำ 으

요 \&

ஃஃ ஃ ஃ ட

요 우

ำ ㅇํํำ

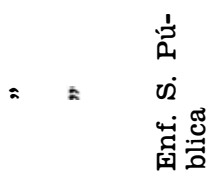

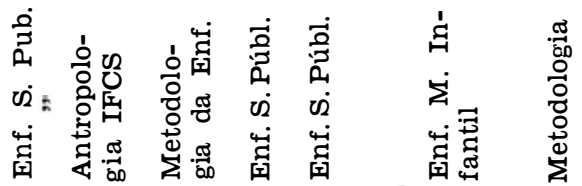

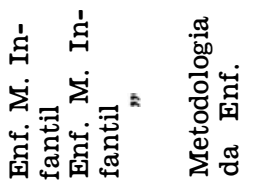

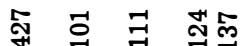

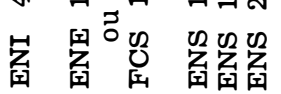

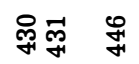

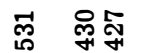

点空 空

宗空空 空

$\infty$ N 0

凅狂 改

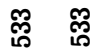

倔 号

o 0

$+\infty \infty$

육 요 윰

웃 \& 8 \&

웅 옥

윽 융유 음

$\infty$

으 ㅇํㅇ ㅇำ ช ช $ะ$ ㅇ

$8 \quad 8$

$\varnothing 8 \%$

ก ก ก

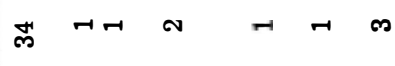

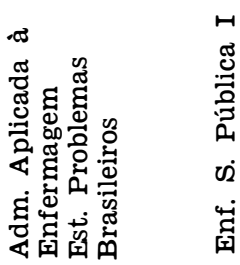

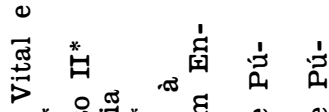
లீ. 윰

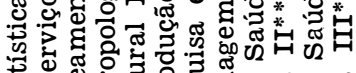

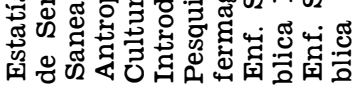

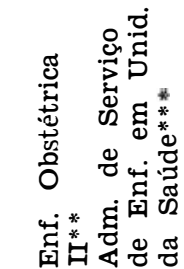

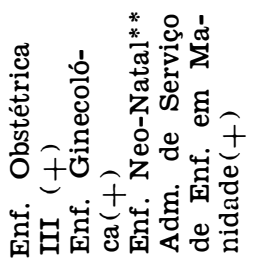

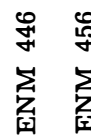

ణ

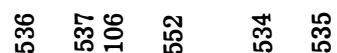

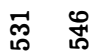

กี้ กิ กิโ

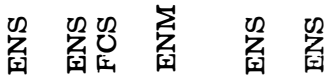

藏宾

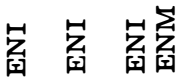




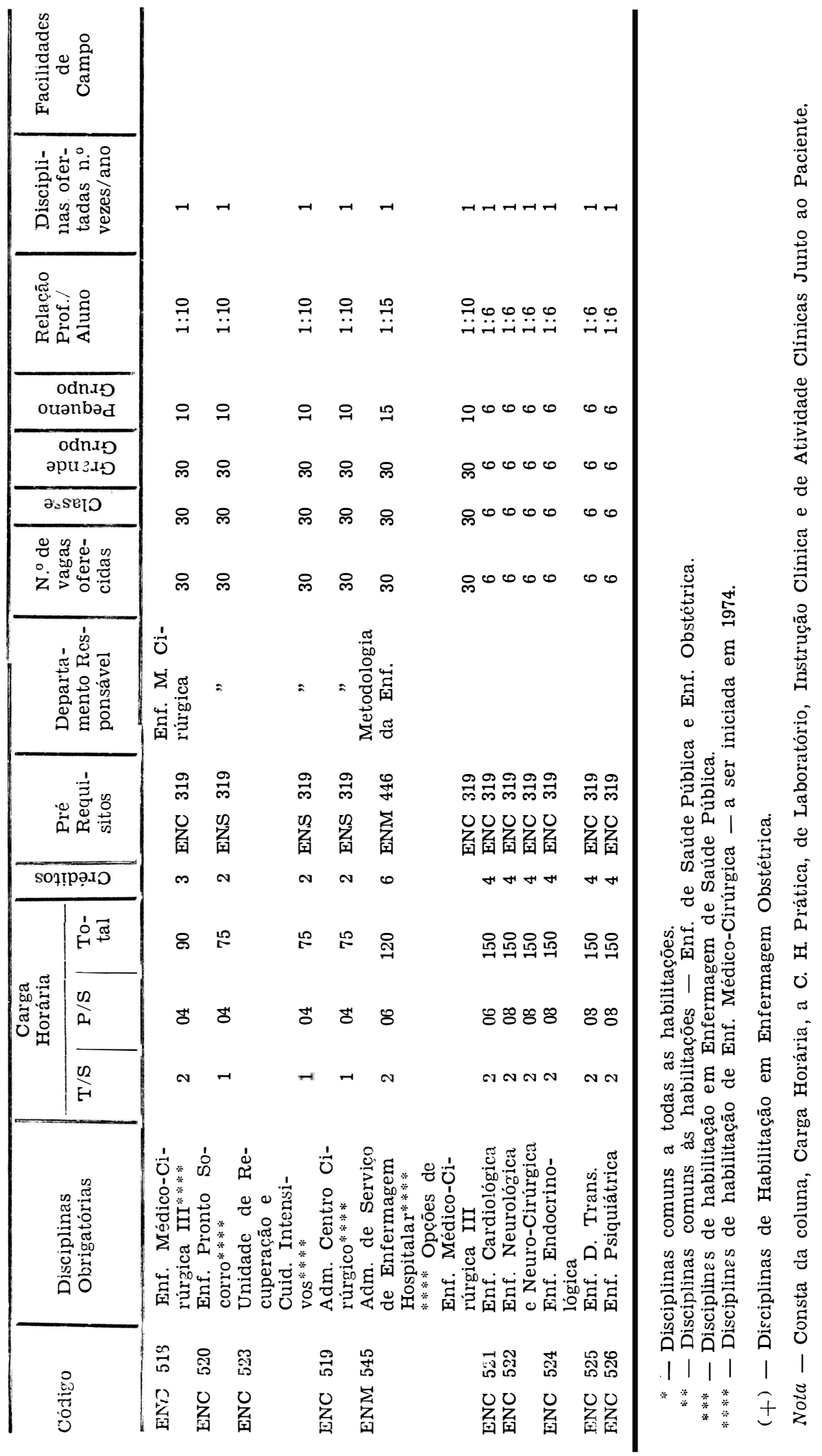


- Conclusão

- Embora alguns esforços estejam sendo mobilizados nos sertido de aplicar um sistema bastante flexível ao ensino de enfermagem, ainda prevalecem abordagens sistemáticas e tradicionais c.cmo opositoras a inovações, ligadas a:
Currículo $\left\{\begin{array}{l}\text { Investigação } \\ \text { Programas e planos de estudo; } \\ \text { Distribuição da carga horária; } \\ \text { Adaptação do pessoal docente; } \\ \text { Disponibilidades materiais; } \\ \text { Desenvolvimento do Corpo Social; }\end{array}\right.$

- A maior soma de dificuldades no desenvolvimento do currículo pleno do Curso de Graduação em Enfermagem continua sendo a falta de sincronização entre o planejamento e organização curriculares e a fase de aplicação em Campos Clínicos;

- O Sistema de Créditos obriga o oferecimento de todas as disciplinas em todos os períodos letivos, o que vem permitir maior flexibilidade no desenvolvimento curricular com aumento do número de alunos na Escola, sem prejuízo da qualidade do ensino;

- As escolas de enfermagem precisam estudar a aplicação do Sistema de Créditos de modo que valorize o esforço do aluno em trabalhos independentes;

- Para atender aos problemas de ensino decorrentes da aplicação do atual currículo e dos preceitos da Reforma de Ensino Superior, as Coordenações de Curso precisam ser estruturadas, permitindo encontro regular dos professores que ministram as disciplinas do I..$^{\circ}$ Ciclo (quando houver, Ciclo Básico, Ciclo Profissional e Habilitações, o que permitirá uma abordagem mais bem dirigida aos objetivcs estabelecidos para o ensino de enfermagem;

- Todos os grupos responsáveis pelo ensino de graduação e cs envolvidos na Assistência de Enfermagem nos Campos Clínicos devem participar da contínua reformulação dos objetivos educacionais e mais particularmente os cperacionais, tendo em vista as principais funções da enfermeira;

- Os objetivos operacionais propostos para o desenvolvimento cas experiências de prática não vêm sendo completamente atingidcs face às dificuldades e problemas nas áreas clínicas de alguns Campos de atividades teórico-práticas e estágio;

- Os Serviços de Saúde utilizados para aplicação prática dcs diversos programas das disciplinas de enfermagem vêm gradativamente reconhecendo o valor da atuação dos professores e alunos de 
Graduação em Enfermagem; entretanto, ainda não têm aproveitado ao máximo a disponibilidade de experiências que esses elementos oferecem;

- As escolas de enfermagem que utilizam os Serviços de Saúde, como campo de prática, vêm reconhecendo o valor desses Campos, cferecendo-lhes as disponibilidades de experiências pela participação como assessoras às Chefias de Enfermagem nos Programas de Treinamento de Pessoal de Enfermagem desses Serviços;

- Os currículos de graduação em enfermagem devem ampliar as oportunidades ao estudante para aquisição de comportamentos apropriados à função de participar de Associações de Classe e Sociedades Científicas;

- É urgente a criação de Cursos de Mestrado para atender a todas as regiōes do país, a fim de preparar docentes para o ensino e pesquisa em enfermagem, face as exigências atuais do ensino de graduação.

\section{REFERENCIAS BIBLIOGRÁFICAS}

BROW, Amy Frances. Curriclum para escuelas de enfermeria. México, AID [c1964].

COMISSÃO CENTRAL DE REVISÃO DOS CURRICULOS, Rio de Janeiro. Parecer n. ${ }^{\circ}$ 163/72, C.C.R. Documenta (135):261-4,fev. 1972.

CONFERENCIA PANAMERICANA DE EDUCACIÓN MEDICA, 3. ${ }^{\mathrm{a}} \mathrm{ed.}$ Buenos Aires, 1970. Publicación final, Buenos Aires, 1970.

RIO DE JANEIRO, Universidade Federal. Regimento Geral. Rio de Janeiro, 1970.

RIO DE JANEIRO. Centro de Ciências Médicas. Informações ao estudante. [Rio de Janeiro] 1973.

RIO DE JANEIRO. Centro de Ciências Médicas. Escola de Enfermagem Ana Néri. Regimento. [Rio de Janeiro] 1972.

RIO DE JANEIRO Superntendência Geral de Ensino de Graduação e Corpo Discente. Resoluções do Conselho de Ensino de Graduação (1969/1970/1971) [Rio de Janeiro] 1972.

SEMINARIO SOBRE ENSEÑANZA DE ENFERMERIA A NIVEL UNIVERSITARIO. Lima. 1971. Informe final. Washington, OPS [1973]. 